\title{
A General Overview on the Far East Cuisine: Guisines of Thailand, Korea and China *
}

\author{
Sevgi Balıkçıoğlu Dedeoğlu*, Şule Aydın, Gökhan Onat
}

\section{ABSTRACT}

\author{
Keywords: \\ Far east cuisine \\ Thailand \\ Korea \\ China \\ Ethnic Food
}

Article History:

Submitted: 04.06.2019

Accepted:07.12.2019

\begin{abstract}
The aim of this study is to examine the Thai, Korean and Chinese cuisines of the Far East. Far Eastern cuisine has a rich culinary culture that has hosted many civilizations that serve as a bridge between past and present. Thai, Korean and Chinese cuisines are the most remarkable ones among the Far Eastern cuisines. Therefore, these three cuisines have been the main focus of this study. In this study, cuisines' history and their development are explained by giving basic information about these three countries. After this step, the general characteristics of the cuisines of these countries are mentioned. Finally, some of the foods that are prominent in these countries and identified with these countries are explained in general terms.
\end{abstract}

\section{Introduction}

With the reflection of postmodern consumption mentality on tourist behavior, national cuisines have reached another level of importance as tourist attractions. Despite the fact that local food has an important place in the past as a touristic product, the benefits gained through authentic experiences are much more at the forefront nowadays. The increase in the benefit that a tourist can get from local food reveals that local food is a subject that needs to be emphasized more.

When the international touristic activities in the world in 2017 are reviewed, it is seen that the number of people participating in touristic activities is 941 million in total from the continents of Europe (672), America (211) and the Middle-East (58). In addition, it can be indicated in the light of the analysis based on the whole continent that international touristic travels are carried out within the confines of the continents themselves (NTWTO, 2018). At this juncture, especially for those individuals who are to participate in the international touristic activities from the continents of Europe, America and the Middle East, the cuisine of Asia and especially the Middle
East can be highlighted in order to be able to attract them to these regions. As a matter of fact, the popularity of many cuisines from the Far East regions is gradually increasing and they are becoming an attraction element. For instance, while various food in Thailand occupy the highest spots in the World's most delicious food ratings, Korea (South Korea) is endeavoring to bring its cuisine to the forefront through the elements that would create cultural awareness on Korean food. China, on the other hand, forms the basis of Far East cuisine. Most Far East countries have been shaped by the influence of Chinese cuisine as a result of the Chinese influence which had been ongoing for years. Therefore, it can be claimed that these three national cuisines should be paid attention to in the context of being marketed as a touristic product.

In this study, three important Far East cuisines have been examined and analyzed. Within this scope, not only the history and cultural development of the countries but also their geographical and climatic characteristics were taken into account, and the processes of formation

\footnotetext{
* Corresponding Author
Sevgi Balıkçŏ̆lu Dedeo ̌̆lu *. PhD Candidate, Nevşehir Hacı Bektaş Veli University, Department of Gastronomy and Culinary Arts

Review Paper

Sevgi Balıkçığ̆lu Dedeoğlu *: PhD Candidate, Nevşehir Hacı Bektaş Veli University, Department of Gas

Prof. Dr., Nevşehir Hacı Bektaş Veli University, Faculty of Tourism, Department of Tourism Management

Prof. Dr., Nevşehir Hacı Bektaş Veli University, Faculty of Tourism,
Email: suleaydin@nevsehir.edu.tr, Orcid Id:0000-0002-8760-643X

Res. Asst., Recep Tayyip Erdoğan University, Faculty of Tourism, Department of Gastronomy and Culinary Arts

$\begin{array}{ll}\text { Gökhan Onat: } & \text { Res. Asst., Recep Tayyip Erdogan University, Faculty of Tourism, Departy } \\ & \text { Email: gokhan.onat@erdogan.edu.tr, Orcid Id: 0000-0001-5072-948X }\end{array}$
} 
of the culinary cultures were tried to be explained. Lastly, general information was presented focusing on the showcase products of these cuisines.

\section{Thailand}

\section{Thailand's General Characteristics}

Thailand, the historical name of which was Siam and the current official name of which is Thailand Kingdom, resides in the central region of the Indochina Peninsula (Mishra, 2010: XI). Indochina peninsula is a region stretching from the east of India in Southeast Asia to the south of China. This is why Thailand has borders with four countries which are Laos in the north, Malaysia in the south, Myanmar in the west and Cambodia in the east (Wikipedia, 2019a).

The archaeological findings suggest that there was habitation in the prehistoric periods in the geographical location that is called Thailand now. It is estimated that agriculture and stockbreeding in this region began approximately 12 thousand years ago. Modern scholars state that the Thailand people came from North Vietnam or China and that they settled in the Southeast Asia as of 8th century (London, 2008: 24). According to another source, it is believed that the Thailand people came from the Altai Mountains in North Mongolia (Moore, 1975: 22). The Thailand people living in the plains and river valleys of the southeastern Asia continent led their lives by fishing in the small villages, growing rice and gathering food from the jungle. While the families living in Thailand villages were comprised of elementary families, the family members worked as rice farmers trying to make their ends meet (London, 2008: 24-25). This situation ensures that Thailand be among the leading countries with regard to rice export in our day (Mishra, 2010).

Although Thailand is the unadulterated center of civilizations such as Egypt, Mesopotamia and China, it is not as well-known as them. However, Thailand is among the first centers of civilization in humankind development (Mishra, 2010). This is why it was home to many different nations. When the Thailand Kingdom was first established, it was influenced by Buddhism and Hinduism religions (Mishra, 2010: 1). Therefore, it can be stated that $90 \%$ of people living in Thailand are Buddhists, and the rest are Muslims, Christians or followers of Sikhism and Hinduism religions. Within the remaining part, the majority is comprised of Muslims (approximately 6\%). Thailand Muslims are not Malaysians. They came from Iran, Pakistan, India, China and the Arabic world (London, 2008: 71). According to 2014 data, Thailand population is comprised of approximately
67 million people (Wikipedia, 2019a). While $75 \%$ of the Thailand population is comprised of ethnic Thais, $14 \%$ is comprised of Chinese and the rest is comprised of other ethnic groups (Malaysian, Indian etc.) (London, 2008: 78).

Thailand is comprised of 6 regions involving Northern, Southern, Western, Central, Eastern and Northeastern Thailand. In the south of Thailand, there is the Gulf of Thailand, and in the west, there is the Andaman Sea. Although there is equatorial climate in a very small region of Thailand, tropical climate is dominant in general. In addition, monsoon climate is seen in the southern regions. While the period between the months of May and October in Thailand goes on with high levels of precipitation with the effect of the monsoon rains, the months of March and April are those times at which the heat and humidity are at their highest in Thailand. A cool climate is seen between the months of November and February (Wikipedia, 2019b).

\section{The History and Development of Thailand Cuisine} The national cuisine of Thailand is called Thailand cuisine (Wikipedia, 2019c). As a result of the Thai cuisine having been in mutual exchange with the cuisines of the neighboring countries, it was influenced by the cultures and hence, cuisines of those countries. It was influenced by Malaysia in the west, Vietnam and Cambodia in the east, the Yunnan region of China and Laos in the north, and Myanmar in the northwest. Thailand cuisine is comprised of four regions involving Northern Thailand, Central Thailand, Southern Thailand and Northeastern Thailand. In addition to these regions, there is Thailand Royal Cuisine, the history of which dates back to ancient and multicultural kingdoms, yet this cuisine generally reflects the characteristics of Central Thailand cuisine. Thailand is the only state that escaped the colonization of western countries in the Southeast Asia region in the Second World War. This attribute enabled their cuisine to preserve its authenticity (Wikipedia, 2019d). On the other hand, the cuisine of relatively western countries influenced Thailand cuisine as well following the beginning of the diplomatic relations with the west. In 1511, with the visit of Portuguese diplomat to the Ayutthaya kingdom, a Portuguese dish called "fios de ovos" was adapted to Thai cuisine as "foi thong". In addition, they encountered Chile peppers for the first time brought from the American continent around the 16th and 17th centuries. The Thailand cuisine, with the influence of the Persian and Indian cuisine, adapted the 
massaman and yellow curry to their cuisine (Wikipedia, 2019c).

\section{General Attributes of the Thai Cuisine}

Since Thai people owned rich agricultural areas throughout their history, Thailand is an agriculture-based country. Rice, on the other hand, forms the basis of Thailand people's agriculture. It is believed that rice cultivation dates back further than 3500 B.C. $60 \%$ of Thailand people do farming today, and most of them cultivate rice (Berno et al., 2019: 18). Although there are nearly 3500 kinds of rice in Thailand today, the most well-known is the jasmine rice (Berno et al., 2019: 19).

While in the Thai culture, rice and fish symbolically represent power (sexual), the abundance and blessings of the country, it also forms the basis of Thai diet. Therefore, these beliefs and culture have been influential in the daily life of the Thai people. Especially the consumption of rice means more than just food, since it is intertwined with the lifecycle of Thai people with regard to religious belief and ritual practices. This is why rice is a holy food for Thai people (Berno et al., 2019: 19). As well as noodles being as equally popular, dishes such as noodle soup fried in wok can be presented in a single plate (Wikipedia, 2019d). The second most important raw ingredient of the Thai cuisine is fish. The main reason is that Thai people constantly inhabited in paddies and watery lands. Fish is even used in dessert-making. For instance, a roasted fish can be consumed with watermelon (Seubsman et al., 2009: 419).

The most significant attribute of Thai cuisine is that preparation of balanced dishes is of great importance (Chongchitnant, 2016). Flat rice or wet rice are served with the spiced Thailand curry or fried dishes in order to balance the spice (Wikipedia, 2019d). There are 6 fundamental points to be aware of with regard to the preparation of the dishes of the Thai cuisine. The first is that some of the dishes need to be watery. That means it needs to be served with soup or curries (sauced or watery dishes). Especially the coconut curry or more bullioned soup can be preferred. Secondly, there needs to be a non-watery piece on the dish such as grill or fry. Thirdly, light and fresh vegetables and herbs should be used. For instance, fresh lemon juice, fresh herbs should be served. Four, there needs to be at least one spice. Five, if there are no noodles, there definitely needs to be rice. Six, by making a mix of products such as fish, meat, shellfish, poultry and vegetables, a more well-balanced dish should be prepared. This is why the balance of the main ingredients should be taken into notice rigorously (Chongchitnant, 2016).

Another important attribute of the Thai cuisine is that dishes are served with the sauce and seasoning called nam chin. Different kinds of sauce can be offered such as fish sauce, lemon juice, chopped red hot chili pepper and garlic, hot pepper chopped in rice vinegar, spiced chili pepper sauce (Wikipedia, 2019d).

Rice is the indispensable ingredient of the Thai cuisine. This is why dishes are served with rice. Rice and the food served next to it are put on the table in a way to let anybody help themselves. The Thai people only take a small piece of the food served and respects everyone's right to get food. As the food on the plate is finished, they can have more small portions and continue eating. While food is being eaten, a spoon and a fork are used. The fork is used to fill the spoon (Chongchitnant, 2016).

\section{The Showcase of Thai Cuisine}

Thai cuisine is among the most well-known cuisines in the world. According to a survey by CNN Travel, a total of seven tastes from Thai cuisine were on the list of "the most delicious 50 dishes of the world". These are tom yam goong, pad Thai, som tam, massaman curry, green curry, Thai fried rice and nu nam tok (Wikipedia, 2019c).

With the "Amazing Thai Taste" festival organized in 2017, it was aimed to promote Thai cuisine and develop tourism. Within this scope, 6 Thai dishes were focused on. These were pad Thai, tom yum goong, green curry, som tam, massaman curry and tom kha kai. In addition, promotional activities were carried out regarding seasonal fruits such as durian, rambutan, magosteen and pineapple (Tourism Authority of Thailand, 2017). As is seen, the prominent dishes are the same as revealed by the surveys carried out by both CNN Travel and the Thailand Tourism Administration. Therefore, it can be stated that the abovementioned dishes come to the mind when it comes to Thailand cuisine.

Pad Thai is among the most well-known dishes of the Thai cuisine. The dish took this name after the country's name being changed from Siam to Thailand. Although pad thai is made using the noodle which belongs to China as an ingredient, it still manages to being known with the name 'Thai'. The main underlying reason here is the desire of the prime minister of Thailand who is known with his Thailand nationalism, to protect its country from the influence of China. The word 'pad' refers 
to frying and mixing with little oil in wok (Chongchitnant, 2016: 277). Pad thai is the rice noodle dish which is cooked on the pan by adding different ingredients (Merriam-Webster, 2019). Eggs, fish sauce, dried shrimp, garlic, red pepper are among the ingredients that can be used while cooking pad thai (Wikipedia, 2019e).

Tom yum goong is a kind of soup named nam sai (Chongchitnant, 2016: 207). While soup in the preparation of which lemon weed is used is called Tom yum, goong refers to shrimp. Therefore, we can call this dish shrimp soup. While the term Tom in the "Tom yum" refers to the process of boiling, yam expresses the spiced/chili and sour salad in the Thai cuisine. This soup is prepared using lemon weed, plump lemon leaves, fish sauce and red pepper flakes. There are a lot of different kinds of tom yum. While tom yum kathi is made focusing on the coconut milk, tom yum pla is the fish soup that is consumed with rice. Tom yum pla was the most prevalent kind of tom yum before the increase in tourism activities. Tom yum kai is the kind which is prepared with chicken (Wikipedia, 2019f).

Som tum, the green papaya salad, is prepared with raw papayas. Spices are used for the preparation of these salads. As in other Southeastern Asia cuisine, the origin of this dish is not exactly known. While "som" expresses sourness, "tum" refers to smashing ingredients in the press. Accordingly, it can be said that some of the ingredients of som tum are prepared by smashing in the press. Since in the salad-making of the West (Europe and America), the ingredients are gently sprinkled, the smashing in this case may be conceived strange. However, this helps the grinding of garlic and peppers (Chongchitnant, 2016: 247). There are a lot of different ingredients used for making of som tum. These are: chili pepper, asparagus bean, garlic, fish sauce, tomato, shrimp spread, jaggery and tahiti lime. Som tum is generally served with rice mash and grilled chicken. Som tum can be used in order to lighten the main course, taking into consideration the balance factor in Thai cuisine (Wikipedia, 2019h).

Massaman curry is not watery and spicy as other curries in Thai cuisine. Massaman curry today is prepared with regular potatoes. However, before the Thai cuisine was introduced to regular potato, yellow sweet potato was the main ingredient of this curry (Chongchitnant, 2016: 175). Massaman curry is a light one as well as a rich one. This curry is prepared using a combination of local riches such as gillyflower, anisee, cumin, bayleaf, cordamon, spices like cinnamon and corriander seed, dried pepper, lemon weed, shrimp spread, garlic and onion. Massaman curry is dedicated to Muslims. This is why different ingredients such as chicken, cattle, sheep and goat meat are used in the preparation of original Massaman curry (Wikipedia, 2019i).

The Green curry takes its name from the fact that it is prepared with green peppers (Chongchitnant, 2016: 163). Since it is made of coconut milk and fresh green peppers, its color is light. In Thai cuisine, this color is called "the sweet green". Therefore, green curry is also called sweet green curry. It has sharper taste in comparison to the red curries. In addition to its main ingredients such as fish, fish meatball or other meat products, the Green curry is made using coconut milk, green curry spread and fish sauce. This curry is prepared by frying in coconut cream oil (Wikipedia, 2019j).

Around the end of 19th century, Tom kha kai was a chicken or duck main course served with plenty of galangale and little coconut milk rather than soup. Yet today, Tom kha kai is fundamentally a kind of soup that is prepared using a combination of coconut milk and spices. In addition to coconut milk, Tom kha kai can be made using galangale, lemon weed, coriander, paddy straw, chicken, fish sauce, lemon essence and kaffif lemon leaf. Occasionally it can be enriched adding fried peppers (Wikipedia, 2019k).

\section{Korea}

Korea's General Characteristics

Although the name Korea in our day and time recalls two countries as North and South Korea, Korea was being run as a single country until the end of the Second World War. Although the history of Korea dates back to 8000 B.C, this date is believed to have begun with the people living in the Manchurian and Korean peninsula. Agriculture started with the people that migrated to the Manchurian and Korean peninsula between the years 2000-1000 B.C. Rice cultivation, on the other hand, started first around the year 700 B.C. in the Korean peninsula (Kim, 2005: XV-XVI).

Korea had to suffer from the influence of different countries such as China, Mongolia, Japan, Russia and the USA. This situation had an impact on the development and shaping of the Korean culture. The geographical and political boundaries of Korea in our day and time were formed after the Second World War. While the Korean Democratic Republic was established in the north of the Korean peninsula with the support of the Soviet Union, the Korean Republic was established in the south of 
the peninsula with the support of the USA (Wikipedia, 2019). Besides the fact that North Korea's surface area is $122.760 \mathrm{~km} 2$, it is located neighboring Russia and China in the north, the Japanese Sea in the east, the Yellow Sea and Korean Republic (South Korea) in the south. The basis of the state management in the country which was established in 1948 goes back to socialism and the population is comprised of approximately 25 million people. In addition, there is a governing mentality that is quite sheltered from the outside world in relation to other governments dominated by socialism (Republic of Turkey Ministry of Foreign Affairs, 2019a; Wikipedia, 2019m). The Korean Republic established in the south has $99.700 \mathrm{~km} 2$ of land and its population is around 51 million 635 thousand (Republic of Turkey Ministry of Foreign Affairs, 2019b). In the east of the South Korea, there is the Japanese Sea and Japan, in the west there is China and the Yellow Sea, in the north there is North Korea (Wikipedia, 2019n). While those who live in the North Korea are all comprised of Koreans, those who live in the South Korea are comprised, to a very large extent, of Koreans. Therefore, it is not possible to mention about a multicultural society influence. In the South Korean climate, winter is relatively cold and dry, and summer is humid. While the temperature goes down as low as on average -5 in the regions away from the coastline in winter months, the average temperature in summer months is approximately 25 degrees. In addition, the annual precipitation rate may reach up to $1500 \mathrm{~mm}$ (Britannica, 2019).

\section{The History and Development of the Korean Cuisine} Since the past periods, food occupies an important position in Korea. In Korea, food represents peace and happiness. As well as rebelling less, well-fed people are more grasping towards rules. For this reason, governments before modern Korea always placed importance on agricultural production. In this context, food has always been important for Korea (Pettid, 2008: 24).

Agriculture in Korea dates back further than B.C. era. Korea started to cultivate grains around midNeolithic Age and rice beginning from 2000 B.C. Since the beginning of the Korean history, beans and rice alongside various grains have been cultivated. In other words, rice, beans and other grains formed the basis of Korean food. Among other grains, there is Italian corn, Chinese corn and kaoliang (African corn). Yet, after rice farming begun, wheat began to be cultivated around the 1st or 2nd centuries. Since the Korean Peninsula is surrounded by sea on three sides and by the intersection of cold and hot currents and it has very large rivers, it is located in a region ripe which is very rich in seafood. Besides, as a result of intense seasonal changes and developments in their skills of processing fermented food such as jeotgal (salted seafood) since the earlier times, they experienced significant improvements in terms of the diversification of seafood. Furthermore, thanks to their high capabilities in hunting, Koreans formed the tradition of preparing meat-based dishes, which is rarely seen in agricultural societies (Robert, 2010: 111).

When these are taken into account, it is seen that regular and daily rice, soup and common side dishes have been developed. The table setting was clearly different for the main and sub-courses. In rituals and festivals, it became a tradition that a table is set up involving every kind of appetizerdinner service, noodle soup flavored with soy sauce, cold noodles, rice cake, honey pastries and drinks. With the influence of the four seasons, food produced in each region and garnitures consumed daily varied from region to region and passed through a developmental phase. Ganjang (Soy sauce), kimchi (pickle), jeotgal (seafood salad) and preservable processed food such as horse radish pickle, cucumber began to be consumed in earlier times (Robert, 2010: 111).

Significant effects of the Three Kingdoms Period are observed in the Korean cuisine. Throughout the Three Kingdoms Period, rice was the most elemental food in the Korean diet. All kingdoms (Goguryeo, Baekje and Silla) supported the soil reform, expanded irrigation systems and actively supported the use of metal tools and equipment in agriculture (Robert, 2010: 115). Especially in the Three Kingdoms Period, the consumption of cattle, pig, chicken, sheep, goat, duck and eggs increased (Robert, 2010: 117).

With Koreans learning how to build a boat in the 3 rd and 4th centuries, the variety of the fish and seafood in Korean cuisine increased. With the development of cooking techniques, Koreans gained experience of preserving and storing products such as wine, pickle (kimchi), seafood brine (jeotgal) and sauce. In addition, around the same centuries, Koreans began diversifying their culinary culture with the use of honey, syrup and liquid oil. The table setting for a typical Korean cuisine developed throughout this period. While the grain, vegetables and meat are offered as main course in this table setup, fish are served as garniture (Robert, 2010: 117-118). 
Horse radish, turnip, lotus roots, leek, lettuce, green onion, water shields, garlic, pearl onion, cucumber and eggplant were cultivated in the Goryeo period. In addition, mountain greens and wild mushrooms were also cultivated and consumed in this period (Robert, 2010: 118-119). Especially the tea culture reached the highest peak in the Goryeo Dynasy period. High quality tea was imported from China and a tea village was built in the Korean region. Tea culture paved the way for pastry (cake and mince pie) culture to develop. Pastries are prepared to a large extent as yumilgwa (fried honey cookie), yugwa (fried cookie made of sticky rice), dasik (small cakes consumed with green tea), jeonggwa (sugar-glazed fruit) and gwapyeon (fruit with jelly). Among these varieties, the most popular one during the Goryeo Dynasty was yumilgwa (Robert, 2010: 119).

In the Joseon Dynasty period, Korean cuisine was both under the influence of Confucius and was introduced to foreign cuisine. With the maturation of Confucius culture beginning from the 16th century, yangban culture expanded and this situation had a significant effect on the Korean culinary culture (Robert, 2010: 121). In this period, Yangban houses also prepared cooking documents and developed cooking methods. During the Joseon dynasty period, Korean cuisine encountered foreign food for the first time such as peppers, pumpkins, potatoes, sweet potatoes and tomatoes. In this period, the fishing techniques were developed further and efficiency in the seas was enhanced. Thus, the influence of fish on the Korean cuisine was felt much more deeply (Robert, 2010: 123).

\section{General Attributes of the Korean Cuisine}

Korean cuisine is a cuisine that has evolved in the Korean Peninsula and south Manchuria region under natural environmental and cultural influences as well as the influence of their agricultural and nomadic traditions. As is seen both in Korean history and the historical development process of the Korean cuisine, it can be indicated that they improved themselves in agricultural products due to the fact that they were engaged in agricultural activities starting from very early times. Furthermore, the nomadic and hunter characteristics of Koreans which they had in the earlier periods enabled them to advance in cooking and consumption of meat products. Although it is not specifically stated that rice cultivation began in Korea, it is expressed that it has been grown in the Korean peninsula for a long time.
In addition, because Korea is located in a peninsula, the surrounding sea and especially the ocean offer plenty of fruitful and varied food. Especially the fermentation and irrigation methods developed in line with the differences varying from region to region have enabled that a wide variety of seafood are consumed as meal in the Korean cuisine (Pettid, 2008: 25). Moreover, many mountains on the peninsula host wild plants and grasses. These plants and herbs are prepared and stored as they are important ingredients. Vegetables can thus be served all year round. As a matter of fact, this method has been sustained since the earliest periods of Korean history (Pettid, 2008: 25).

Taking into consideration the above-mentioned remarks, it can be claimed that Korean cuisine is predominantly based on grains (mostly rice) flavored with spiced vegetables, meat, poultry or fish dishes. The Korean cuisine is notable for five kinds of taste (salty, sweet, sour, chili and hot) and color (red, green, yellow, white and black) (Britting, 2011: 164). The ingredients and food in the Korean cuisine developed on regional basis as mentioned before. For this reason, the dishes that were previously regional were created with differences as they spread throughout the country. Another important attribute of the Korean cuisine is that it embraces the close relationship between health and food (Pettid, 2008: 26)

Although Korean cuisine maintains its continuity in certain aspects, it has undergone great changes in the last century. Especially, trade agreements with France, Britain and other Western countries allowed new cultural experiences. In addition, a lot of people joined the royal family as a counselor, doctor or missionary. Thus, the educational and scientific knowledge gained has paved the way for the discovery of western food. However, many schools built by western missionaries introduced western culture, including western food. Although rice is a very important and essential food for Korean cuisine, its consumption has decreased considerably in recent years. Meat consumption increased from $5.2 \mathrm{~kg}$ per person in 1970 to $40 \mathrm{~kg}$ in 1997. In addition, Koreans consume an average of $49.5 \mathrm{~kg}$ of fish per person per year. Meat dishes, once stored for special occasions and guests, are now consumed on a daily basis (Pettid, 2008: 166).

In Korean cuisine, meats are often greased before cooking. Marinated beef is grilled on a barbecue or on a stove. In terms of meals, typically, breakfast, 
lunch and dinner are available. Breakfast may include soup, rice oat soup and kimchi, while lunch includes noodles or gravy and rice as a side dish. For dinner, fish or meat along with rice, kimchi, soup and two or three types of vegetables could be offered. Bowls are provided for each of the main course. Barley juice or tea can be served after the meal (Brittin, 2011: 164).

\section{The Showcase of Korean Cuisine}

Although there are various dishes in Korean cuisine, the eight best known tastes are kimchi, bibimbap, bulgogi, bossam, japchae, haemulpajeon, makgeolli, and samgye-tang (K-Food, 2015: 95-130).

Kimchi is undoubtedly the most delicious dish of Korean cuisine. There is almost no fat included in this vegetable dish, but it is enriched in flavor and nutrition thanks to the abundance of spices and seafood added to the meal. In addition, the spicy taste and glittering pie texture complete almost all Korean dishes and it is permanent in addition to bap (cooked rice) in Korean cuisine (K-Food, 2015: 95). In essence, a meal in Korea is not complete without the presence of kimchi on the table. Currently, there are officially 187 kimchi varieties in Korea. Koreans consume an average of 40 kilograms of kimchi per year. Kimchi is prepared with pickled and seasoned vegetables to be left to ferment. This fermentation process creates a significant complex flavor that combines spices, thong, sweetness and brittleness. The most wellknown kind is made from Korean cabbage or napa cabbage. Although this food is generally preferred raw, it can also be served in combination with soup, stew and frying (Joo, 2016: 26).

Bibimbap is a food prepared by mixing food and pepper paste with boiled rice (Robert, 2010: 28). In fact, bibimbap is a simple rice dish. It is mixed with spicy vegetables and red hot pepper sauce. This food can be considered unique as it combines ordinary ingredients to create a wonderful and delicious meal. One can adapt this food in a way to fit to his own taste. The traditional Bibimbap plate includes steamed rice with a range of high-quality ingredients such as various nougats (spicy vegetables) and yukhoe (beef tartar) (K-Food, 2015: 105).

Bossam, is a pork dish. This meal is prepared by wrapping into kimchi. The Bossam requires a special preparation technique and contains extra ingredients such as kimchi, oysters, raw chestnuts, jujube, pine nuts and a little more sugar than the standard kimchi flavor. Therefore, it can be stated that it is sweeter than ordinary kimchi (K-Food, 2015: 112).

Japchae is a combination of two words. "Jap" means mixing or collecting various things, while "chae" refers to vegetables. Japchae is one of Korea's leading party dishes and is always featured at festive tables. Made from a combination of stirfried glass noodles and vegetables, japchae is prepared with dangmyeon, a type of cellophane noodle, usually made from sweet potato starch, and noodles are filled with various vegetables, meat and mushrooms and poured with soy sauce and sesame oil and poured spices (K-Food, 2015: 115).

Pajeon is a kind of crepe the main ingredient of which is green onions. For preparation of HaemulPajeon, on the other hand, meat, fish or vegetables (other than green onions) are used. This dish is cooked by shallow fry on the grill. It is prepared by cutting the ingredients into bite-sized pieces before frying, or by mixing the ingredients with dough and water and giving them the shape of crepes. Haemul-pajeon can also be served with sour sauce made with vinegar (K-Food, 2015: 117).

Makgeolli is among the most popular alcoholic beverages of Korean cuisine. This beverage has the soft texture of cream, the fizziness of a carbonated beverage, and a suitable alcohol content ranging from six to seven percent. It is made by fermenting sweet rice. Makgeolli is the oldest alcoholic beverage in Korean cuisine. This drink was the most consumed alcoholic beverage in North Korea between the $1960 \mathrm{~s}$ and $1970 \mathrm{~s}$, but lost its popularity with the import of alcoholic beverages in the 1970s. In the 21st century, this beverage has become popular again among young people (Wikipedia, 2019; K-Food, 2015: 120).

Samgye-tang is hot chicken soup with ginseng. It contains a small but whole chicken. Also garlic, rice, jujube and ginseng are included as additional ingredients. In addition, the banchan is also a very popular flavor. In Korean cuisine, Banchan is the overall name for all small side dishes served with cooked rice. The Banchan is served in the middle of the entire table with small portions. Kimchi is one of the most well-known banchans.

\section{China}

\section{China's General Characteristics}

Despite the fact that civilizations such as Sumerian and Egypt are among the most ancient civilizations in the world, China is the most ancient living civilization in the world (Wright, 2011: 11). In ancient China, traces of the Neolithic period are abundantly observed. Much evidence, such as 
agriculture, the presence of villages, the presence of ceramics and stone tools, supports the fact that China is a deeply-rooted ancient civilization. More particularly, the structural features shaped in line with environmental conditions by habitants living in East Asia come to the forefront more. For example, while people settling along Yangzi river valley usually grew rice, those residing in the Wei and Yellow river valleys cultivated different varieties of corn and cereals. On the other hand, people living on the beach used to consume mostly seafood besides fruit and vegetables (Major and Cook, 2017:2).

Despite not being fully clear, the first dynasty founded in China (Xia dynasty) was reported to have existed around 2100 B.C. It is emphasized that the first dynasty (Shang Dynasty), about which there is evidence regarding its foundation and scientists have reached a consensus over, dates back to 1700-1600 B.C. The Shang Dynasty was later conquered by the Zhou Dynasty (Wright, 2011: 13; Zhang, 2015: 24). The Zhou Dynasty was also weakened and divided by different rebellions. Following this division, small states in China fought for years to establish their superiority. The Chinese Dynasty was established as a result of Qin conquest over other states; however, this dynasty collapsed and left the governance to different dynasties. Until the foundation of the Republic of China in 1912, the empire period continued in China. It can be said that the foreign states had scarcely any influence on China until this period. China was conquered only by the Mongols in 1271 . Furthermore, China had problems with Britain, France and Japan in the late 1800s. After being defeated as a result of the wars with Britain and France, these countries were granted with great privileges over China. China, which lost its influence on the Korean peninsula after the war with Japan, turned over the governance of Taiwan to Japan. Although the Republic of China was established in 1912, the People's Republic of China was founded in 1949 and seized the power of governing. There is currently a dispute between the Republic of China and the People's Republic of China. Hainan and the surrounding islands, particularly Taiwan, are under the control of the Republic of China, while all other geographical areas are governed by the People's Republic of China. The People's Republic of China claims that the regions under the control of the Republic of China are also under its governance because of the Single China Policy it advocates (Wikipedia, 2019).
As mentioned earlier, China has often experienced wars of sovereignty within its own boundaries. For this reason, it cannot be argued that it was under the sovereignty of foreign states, or foreign states had much influence on Chinese culture. Therefore, there is more variety in ethnic groups constituting the Chinese population; however, it is not much in overall proportion. China's population is approximately 1 billion 390 million. The number of Han Chinese is around 1 billion 150 million. The rest includes people from other nations such as Manchu, Uighur, Hui, Miao, Yi, Tujia, Mongol (Wikipedia, 2019).

China is the second largest country in the world with an area of approximately 9 million 600 thousand km2. China has borders with 14 countries including Afghanistan, Bhutan, Burma, India, Kazakhstan, North Korea, Kyrgyzstan, Laos, Mongolia, Nepal, Pakistan, Russia, Tajikistan and Vietnam. It also neighbors with South Korea, Japan, Vietnam and the Philippines through its sea borders. In addition, it has 690 thousand $\mathrm{km} 2$ of arable agricultural land (CIA, 2019).

Climate in China generally reflects the characteristics of humid monsoons and dry seasons. Due to its vast geographical area, China experiences different climatic conditions. Particularly humid monsoons and dry seasons lead to very distinct temperatures between summer and winter. With the influence of the Yellow Sea and the East China Sea in the east of China, both the population density and the number of alluvial plains are high. Yellow River and Yangtze River are located in the east of China. These rivers feed large deltas. However, the biggest threat to agriculture in China is the annually increasing number of deserted land (Wikipedia, 2019)

\section{The History and Development of Chinese Cuisine}

It is estimated that the roots of Chinese cuisine dates back to the Yangshao culture between 5000 and 3200 BC. In ancient times, the people of Chinese civilization formed their own cooking and eating styles. As mentioned earlier, the fact that China has been a living civilization since ancient times and maintained its geographical location over years led Chinese people to attach great importance to their cuisine. In the early years of Chinese cuisine, rice and corn cultivation comes to the forefront. With the arrival of wheat in West Asia in 2000 BC, Chinese cuisine was introduced to wheat (Chang, 1979: 25). Especially during the dynasty, Chinese cuisine entered a period of extensive development. Throughout the history of 
China, aristocrats and mandarins were influential in the development of Chinese cuisine, as they had always been economically and politically privileged to lead the development of gastronomy (Hong, 2014: 16).

In the Han Dynasty, methods were developed for cooking, frying and drying of cereals, as well as for preserving and storing food. During the Song Dynasty, the importance of rice and rice soup increased relatively. During the Yuan and Qing Dynasties, casserole dishes, which are significant flavors of Mongolian and Manchu cuisine, came to the forefront. Towards the end of the imperial period, raw ingredients such as Mexican peppers, potatoes and corn were introduced to China via the traders from Spain and Portugal (Wikipedia, 2019p).

\section{General Attributes of Chinese Cuisine}

Chinese cuisine embodies wide variety of food due to not only the existence of different agricultural lands provided by the geographical size and the climatic diversity of the country but also hosting different nationalities within its boundaries. It is reported that there are approximately 10 thousand kinds of food in Chinese cuisine. Due to its large surface area, each region may have its own food culture. Therefore, Chinese cuisine consists of different regional cuisine (Polat, 2017: 88). Among these different cuisines, the most effective ones are Cantonese, Shandong, Jiangsu and Sisuan cuisines. While Jiangsu cuisine prefers cooking food at low heat, Sichuan cuisine prefers different baking techniques for food preparation (Wikipedia, 2019p). Especially in the northern regions, naturalness in meals is in the forefront. Therefore, soy sauce, garlic, green onions, sesame oil and spice varieties are the most commonly-used ingredients for sauces. In the southern regions, the use of wok is more prominent. Another important characteristic of the Southern cuisine is the sweetsour sauces prepared on the basis of the unity of contrast. Different techniques of frying dominate the cuisines in eastern China. Especially rice, salads and pastries are consumed along with meals. In the Western region, bitter dishes abundant in spices are consumed. In addition, these dishes may be served accompanied by desserts the content of which are very rich in vinegar and spices (Tez, 2019:21).

It can be indicated that rice is the main foodstuff in traditional Chinese cuisine. Despite the fact that many different ingredients are used in Chinese cuisine, soybean and soybean derivatives occupy a very important position. Soy sauce, soy milk, bean sprouts and Tofu cheese prepared by heating and precipitating curd cheese made from soy milk are some examples of soybean derivatives. Chinese cuisine also has unique vegetables such as Chinese cabbage, Chinese broccoli, and Chinese water chestnuts (Guripek, 2016: 262).

Common meat varieties used in Chinese cuisine include chicken and pork (Güripeki 2016: 262). Pork meat consumption corresponds to $3 / 4$ of overall meat consumption within the country; therefore, it is the most consumed variety of meat. Moreover, insects, snakes, dog meat, cat meat and meat of various wild animals are also consumed in Chinese cuisine (Tez, 2018: 19).

Appearance is also quite important in Chinese cuisine. The harmony of colors, flavors and spices in dishes have a critical role in reflecting Chinese cuisine (Hong, 2014). In Chinese culinary arts, color (aesthetics and beauty), flavor and taste are the fundamental elements. The fact that one of these fundamental elements is missing could lead to unsatisfactory dish. In order for dishes to look appealing to the eye, two or three additional ingredients in different colors must be included along with a single main ingredient (Junru, 2005: 2). Blue, green, red, yellow, white, black and brown sauce colors need to be mixed in the right combination. Furthermore, aesthetic in dishes can be ensured with the help of appropriate cooking techniques. Especially in Chinese cuisine, there is a close relationship between colors and health. This situation comes to the forefront more when fruits and vegetables are involved as an ingredient into the food mix (Hong, 2014: 20). The flavor is ensured by the use of right spices such as green onions, ginger, garlic, wine, anisee, cassia, black pepper, sesame oil and shiitake mushrooms. While the dish is being prepared, techniques such as frying, frying on pan, poaching, quick-frying and boiling can be used in order to preserve the dishes' natural taste and juice. In addition, if the right amount of soy sauce, sugar, vinegar and various spices are used, the saltiness, sourness, sweetness and spiciness of the dishes can be highlighted more (Junru, 2005: 3).

In Chinese table setting, special eating sticks are used instead of forks and knives. This is why ingredients are chopped into big pieces first (around the size of an average bite) before getting scorched in order to ease the cooking process. Duration of cooking is short in Chinese cuisine. In this way, they avoid losing much of the nutritional values of the dishes. Indeed, one of the most important matters to be paid attention to is a 
healthy diet. Therefore, the preparation of balanced dishes can be considered as an important detail in the context of Chinese cuisine. In this regard, dishes are cooked in hollow pans called "wok" at high temperatures. As a result of high temperature, the sugars in ingredients get caramelized and become more delicious. In addition, when the vegetables are being blasted, the inner part of it is left raw while the outer part is fried. Another cooking method is steaming. Steaming is generally used for fish, vegetable and dim sum cooking (Tez, 2019: 21).

In Chinese cuisine, first the salty foods are served. While dry dishes are consumed before juicy and saucy dishes, heavy dishes are eaten before lighter dishes (Tez, 2019: 22). Among the most important features of Chinese cuisine, traditional sticks are used instead of forks and knives in the consumption of the dishes. The English name of which is "chopsticks", the names of these traditional food sticks vary locally as waribashi, kuaizi and hashi. The reason underlying the use of the chopsticks is that the most elemental foodstuff is rice (Albala, 2012: 113).

In Chinese cuisine, they sit at the dining tables according to Chinese customs and traditions. While eating, the person must be sitting. If individuals from all ages and genders are to sit at the same table, elders should be the ones to sit first. Talking is not welcome during dining. Although these proprieties have lasted to our day and time, it is seen that there is a slow wave of changes emerging (Junru, 2005: 5).

\section{The showcase of Chinese cuisine}

Chinese cuisine can produce many different dishes because of its cultural heritage. The most wellknown dishes are Peking duck, sweet and sour pork, Kung Pao chicken, Mapo Tofu, wontons (patties), chow mein (noodle dish) and spring rolls (Chinahighlights, 2019).

Peking duck has been prepared since the imperial period and it occupies the position of the national dish of China. The dish, which used to be cooked for the emperor in the period of Yuan Dynasty was later developed in the Ming dynasty. In the Qing Dynasty period, the fame of the dish reached all the way to the aristocracy. This dish has two important aspects. The first is the raising of the duck and the second is the cooking of the dish. The ducks used for this dish are slaughtered after at least 65 days of breeding. Whereas they are allowed feeding freely during the first 45 days, they are forced to be fed 4 times a day in the last 20 days. The duck, having been rendered ready to be slaughtered, is cleaned with water after the slaughtering and it is dipped in boiling water for a short while before the drying process. Later the duck is hung and glazed with malt syrup. Following this stage, the duck is cleaned with water again and the second glazing stage begins. In the second glazing stage, it is left to dry in a dry and cool environment for 24 hours after it is glazed with soy sauce, various spices and more malt syrup. Lastly, it should be cooked in a closed or open oven until it turns brown (Wikipedia, 2019v).

The sweet and sour pork dish derives its taste from a combination of sweet sauce and sour sauce. Although sweet and sour sauce is prevalently used in China, it has been used in England since the medieval age as well. However, it is claimed that the sweet and sour sauce of China comes from the Hunan state. Although the most well-known dish with sweet and sour sauce is made of pork, it can be consumed with other meat varieties and fish. Sweet and sour sauce is prepared with rice vinegar, salt, Chinese brown sugar, ketchup, Worcestershire sauce and dense soy sauce (Wikipedia, 2019r).

Kung Pao chicken is also known as Gong Bao or Kung Po. For the preparation of this dish, chicken, peanut, vegetables and spices with hot pepper are used. While only plain leek included as a vegetable, the food needs to be cooked by frying on the pan. Kung Pao chicken is offered as a classic dish of the Sichuan cuisine. It is estimated that the dish emerged after the Ding Baozhen, the governor of the Sichuan state (Wikipedia, 2019s).

Mapo Tofu is a dish served with minced meat made of pork or beef and fermented fava bean, paprika paste and inside a spiced sauce which has a black bean base and generally a thin, oily and shiny red colour. While serving this dish, other ingredients such as caltrop, onion and black knot mushroom can be used. In order for this flavor to be impeccably presented, the hot fava bean paste brought from Sichuan, fermented black bean, pepper oil, Sichuan black pepper, garlic, green onion and rice wine should be used (Wikipedia, 2019 ş). Tofu is made of the sediment of the soy milk made of soy beans. This sediment is made into a milk curd by mixing it with an ingredient called nagari. It can be used in all meals because it embodies the taste of every food it comes together with.

Wonton can be defined as a patty or mince pie according to its preparation and cooking method. 
For the filling used making wonton, generally ground pork meat or shrimp is used. In addition, it is seasoned with salt, spices and thinly chopped garlic or green onion. This dish is generally served by boiling in a soup or frying. Wonton exhibits significant variations according to regions. For instance, the one in the Canton cuisine in which shrimp filling in shredded pork meat is used is the most preferred variation. In Shanghai cuisine, on the other hand, wonton which is prepared using minced meat filling is prepared along with chicken soup (Wikipedia, 2019t).

Chow mein is a noodle dish fried on the pan. There are different kinds of chow mein, with chicken, tofu, vegetables or soy sauce. In addition, the Chinese who went abroad with different reasons adapted their cuisine cultures according to the regions they settled in. For this reason, chow mein dish may be served differently depending on the region. For instance, in the U.S.A's culture of consuming Chinese cuisine, this dish is generally served with meat, onions and celeries.

Spring roll is the famous Chinese minced pie. This dish which is generally served on an ordeuvre plate can be considered similar to the Turkish deep fried rolls with cheese filling. Although this minced pie has different kinds depending on the region, what needs to be known generally is that it is cooked with the method of frying. As the Chinese spring roll can be prepared sweet or salty, it can be prepared with vegetables as well. It is generally served with pork, carrots, beans and Worcestershire sauce in the regions of Hong Kong and Makao (Wikipedia, 2019ü).

\section{Conclusion and Suggestions}

In this study, general reviewing has been carried out on the Thai, Korean and Chinese cuisines which are among the Far East cuisine, with the aim of attracting international tourists to visit these regions. In the light of the review, it can be stated that all three national cuisines have idiosyncratic features. In Thai cuisine, it is quite important to prepare balanced dishes. Especially Pad Thai and tom yum goong are among the most well-known dishes. Furthermore, Thai cuisine comes to the forefront with massaman and green curries which it has developed by the influences of different cultures. This recognition/familiarity can be quite important in terms of destination visits. Indeed, Lertputtarak (2012) in a study ascertained that tourists' image perceptions concerning Thai cuisine positively affected their revisiting intentions. However, another important aspect that Thai cuisine should be careful about is that
Thai dishes in oversea countries are prepared by people who do not have Thai origin. This situation can cause the Thai dishes to be misconstrued and may lead to wrong image formations in the minds of individuals (Sunanta, 2005: 13).

The fact that five kinds of taste (salty, sweet, sour, chili and hot) are dominant in Korean cuisine is one of the most important features distinguishing the Korean cuisine from others. For Korean culture is increasing its popularity in the world day by day, dishes of Korean cuisine such as kimchi and bibimbap have been rising to the forefront. With this popularity increasing, the number of studies conducted on Korean cuisine has also increased. For instance, Hwang et al. (2018) put forward in a study conducted on American consumers that three basic factors are effective in the Korean cuisine preferences of individuals. These are (1) health, (2) novelty and variety and (3) socio-cultural factors. Hwang et al. also ascertained that dishes belonging to the Korean cuisine are more predominantly preferred by individuals at or under the age of 20 , women, Asians and high-school students. It is especially possible with the effect of hallyu (South Korean Wave) that the Korean cuisine comes or is brought to the forefront more. Seo et al. (2017) in a study conducted on Korea revealed that the cognitive perceptions (health, quality, appeal) regarding dishes are more effective for eastern people to consume local dishes.

The fact that contrasting flavors are used on dining tables considering the principle of the unity of contrast in the Chinese cuisine is an important distinctive attribute of this cuisine. At the top of the dishes that come to mind when Chinese cuisine is mentioned is Peking duck. Besides, Mapo tofu and spring roll rank among the Chinese dishes known with their different varieties. However, the common attributes of the cuisines should not be ignored, either. Rice serves as the basic ingredient in these three national cuisines. There are scarcely any dishes without rice on the dining tables. Rice is consumed generally instead of bread. In addition, tea is indispensable for the abovementioned cuisines, especially for China and Korea. It can be consumed at every meal.

At this point, it can be stated that these three national cuisines should market their unique attributes well. Indeed, whereas Thailand has been receiving benefits since it has been focusing on this since the 1970s, Korean and Chinese cuisine need to show higher tendency towards the matter in question. Although Chinese cuisine is relatively well-known, it can be expected to be in a better 
position with 10 thousand kinds of dishes as well as having a very rooted and rich cuisine culture. In addition, it is considered that Korea will be able to present its cuisine to more people in the coming years with the influence of hallyu.

\section{References}

Albala, K. (2012). Three World cuisines: Italian, Mexican, Chinese. Altamira Press: Plymouth, UK.

Berno, T., Dentice, G., \& Wisansing, J. J. (2019). Kin kao laew reu young ('Have You Eaten Rice Yet')?: A New Perspective on Food and Tourism in Thailand. In Food Tourism in Asia (pp. 17-30). Springer, Singapore.

Britannica (2019). South Korea https://www.britannica.com/place/South-Korea

Brittin, H.C. (2011). The food and culture around the World handbook. Prentice Hall: Upper Saddle River, New Jersey, USA.

Chang, K.C. (1979). Food in Chinese culture: Anthropological and historical perspectives. Yale University Press, London, UK.

Chinahighlights (2019). 8 Tasty Chinese Dishes: the Most Popular Chinese Foods. https://www.chinahighlights.com/travelguide/chi nese-food/eight-chinese-dishes.htm son erişim tarihi: 07.04.2019

Chongchitnant, P. (2016). Hot Thai kitchen. Appetite, Canada.

CIA (2019). The World Factbook, China. https://www.cia.gov/library/publications/theworld-factbook/geos/ch.html

Güripek, E. (2016). Uzak Doğu ve Avustralya Mutfağı. Gastronomi ve Turizm içinde editörler Kurgun Hülya ve Bağıran Özşeker, Demet (s. 259-282). Detay Yayıncllık: Ankara

Hong, T.P. (2014). At home with Chinese cuisine. AuthorHouse, Bloomington, IN, USA.

Hwang, J., Kim, S., Choe, J. Y., \& Chung, C. H. (2018). Exploration of the successful glocalization of ethnic food: a case of Korean food. International Journal of Contemporary Hospitality Management, 30(12), 3656-3676.

Joo, J. (2016). Korean Food made simple. Houghton Mifflin Harcourt, New York, USA.

Junru, L. (2005). Chinese foods. China International Press, China.

K-Food (2015). Korean Culture no.9: K-Food Combining Flavor, Health, and Nature. Korean Culture and Information Service, Korean.

Kim, D. K. (2005). The history of Korea. Greenwood Publishing Group, London, UK.
Lertputtarak, S. (2012). The relationship between destination image, food image, and revisiting Pattaya, Thailand. International Journal of Business and Management, 7(5), 111-121.

London, E. (2008). Thailand Condensed: 2,000 Years of History \& Culture. Marshall Cavendish International Asia Pte Ltd.

Major, J.S. \& Cook, C.A. (2017). Ancient China: A History. Routledge: New York, USA.

Merriam-Webster (2019). Pad Thai. https://www.merriamwebster.com/dictionary/pad\%20thai son erişim tarihi: 07.04.2019

Mishra, P. P. (2010). The history of Thailand. ABCCLIO.

Moore, R.F. (1975). Thailand Malaysia Singapore: People, places, history. Thai-American Publishers: New York.

Pettid, M. J. (2008). Korean cuisine: An illustrated history. Reaktion Books: China.

Polat, S. (2017). Uzakdoğu ve Avustralya Mutfağı. Uluslararası Gastronomi içinde editörler Sarışık, Mehmet ve Özbay, Gülçin (s.83-110). Detay Yayıncllık: Ankara.

Robert, K. (2010). Traditional Food: A taste of Korean Life. The Korea Foundation: Seoul, Korea.

Seo, S., Yun, N., \& Kim, O. Y. (2017). Destination food image and intention to eat destination foods: a view from Korea. Current Issues in Tourism, $20(2), 135-156$

Seubsman, S. A., Suttinan, P., Dixon, J., \& Banwell, C. (2009). Thai meals. In Meals in science and practice (pp. 413-451). Woodhead Publishing.

Sunanta, S. (2005, October). The globalization of Thai cuisine. In Canadian Council for Southeast Asian Studies Conference, York University, Toronto ( $p$. 3).

Tez, Z. (2018). Lezzetin tarihi: Geçmişten bugüne yiyecek, içecek ve keyif vericiler. Hayykitap: İstanbul.

Tourism Authority of Thailand (2017). https://www.tatnews.org/2017/05/amazing-thaitaste-festival-2017-showcase-authentic-cuisinethailand/ son erişim tarihi: 07.04.2019

Türkiye Cumhuriyeti Dış İşleri Bakanlığı (2019a). Kuzey Kore: Ülke Künyesi. http://www.mfa.gov.tr/guney-kore-kunyesi.tr.mfa

Türkiye Cumhuriyeti Dış İşleri Bakanlığı (2019b). Güney Kore: Ülke Künyesi. http://www.mfa.gov.tr/kuzey-kore-kunyesi.tr.mfa

UNWTO (2019). UNWTO Tourism Highlights 2018 Edition. Madrid: UNWTO. 

Wikipedia $\quad$ (2019a).
http://www.wikizero.biz/index.php?q=aHR0cHM
6Ly90ci53aWtpcGVkaWEub3JnL3dpa2kvVGF5b GFuZCNEaW4 last accessed: 07.04.2019

Wikipedia (2019b).

Thailand. http://www.wikizero.biz/index.php?q=aHR0cHM 6Ly9lbi53aWtpcGVkaWEub3JnL3dpa2kvVGhha WxhbmQ. last accessed: 07.04.2019

Wikipedia (2019c). Thai cuisine. http://www.wikizero.biz/index.php?q=aHR0cHM 6Ly9lbi53aWtpcGVkaWEub3JnL3dpa2kvVGhha V9jdWlzaW51 last accessed: 07.04.2019

Wikipedia (2019d). Tayland mutfağı. http://www.wikizero.biz/index.php?q=aHR0cHM 6Ly90ci53aWtpcGVkaWEub3JnL3dpa2kvVGF5b GFuZF9tdXRmYcSfxLE last accessed: 07.04.2019

Wikipedia (2019e). Pad thai. http://www.wikizero.biz/index.php?q=aHR0cHM 6Ly9lbi53aWtpcGVkaWEub3JnL3dpa2kvUGFk X1RoYWk last accessed: 12.04.2019

Wikipedia (2019f). Tom yum. http://www.wikizero.biz/index.php?q=aHR0cHM 6Ly9lbi53aWtpcGVkaWEub3JnL3dpa2kvVG9tX 3lhbQ last accessed: 12.04.2019

Wikipedia (2019h). Green papaya salad. http://www.wikizero.biz/index.php?q=aHR0cHM 6Ly9lbi53aWtpcGVkaWEub3JnL3dpa2kvR3J1Z W5fcGFwYXlhX3NhbGFk last accessed: 12.04 .2019

Wikipedia (2019i). Massaman curry. http://www.wikizero.biz/index.php?q=aHR0cHM 6Ly9lbi53aWtpcGVkaWEub3JnL3dpa2kvTWFzc 2FtYW5fY3Vycnk last accessed: 12.04.2019

Wikipedia (2019j). Green curry. http://www.wikizero.biz/index.php?q=aHR0cHM 6Ly9lbi53aWtpcGVkaWEub3JnL3dpa2kvR3JlZ W5fY3Vycnk last accessed: 12.04.2019

Wikipedia (2019k). Tom kha kai. http://www.wikizero.biz/index.php?q=aHR0cHM 6Ly9lbi53aWtpcGVkaWEub3JnL3dpa2kvVG9tX 2toYV9rYWk last accessed: 12.04.2019

Wikipedia (2019l). History of Korea. http://www.wikizero.biz/index.php?q=aHR0cHM 6Ly9lbi53aWtpcGVkaWEub3JnL3dpa2kvSGlzd G9yeV9vZl9Lb3JlYQ

Wikipedia (2019m). North Korea. http://www.wikizero.biz/index.php?q=aHR0cHM 6Ly90ci53aWtpcGVkaWEub3JnL3dpa2kvS3V6Z XlfS29yZQ

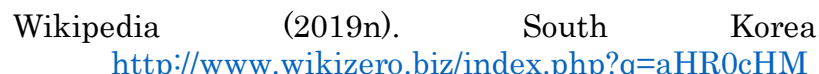
http://www.wikizero.biz/index.php?q=aHR0cHM GhfS29yZWE
Wikipedia (2019o). Makgeolli. http://www.wikizero.biz/index.php?q=aHR0cHM 6Ly9lbi53aWtpcGVkaWEub3JnL3dpa2kvTWFrZ 2VvbGxp

Wikipedia (2019p). Chinese cuisine. http://www.wikizero.biz/index.php?q=aHR0cHM 6Ly9lbi53aWtpcGVkaWEub3JnL3dpa2kvQ2hpb mVzZV9jdWlzaW5l

Wikipedia (2019r). Sweet and sour. http://www.wikizero.biz/index.php?q=aHR0cHM 6Ly9lbi53aWtpcGVkaWEub3JnL3dpa2kvU3dlZ XRfYW5kX3NvdXJfcG9yaw

Wikipedia (2019s). Kung Pao chicken. http://www.wikizero.biz/index.php?q=aHR0cHM 6Ly9lbi53aWtpcGVkaWEub3JnL3dpa2kvS3VuZ 19QYW9fY2hpY2tlbg

Wikipedia (2019s $)$. Mapo doufu. http://www.wikizero.biz/index.php?q=aHR0cHM 6Ly9lbi53aWtpcGVkaWEub3JnL3dpa2kvTWFw b19kb3VmdQ

Wikipedia (2019t). Wonton. http://www.wikizero.biz/index.php?q=aHR0cHM 6Ly9lbi53aWtpcGVkaWEub3JnL3dpa2kvV29ud $\underline{\mathrm{G} 9 \mathrm{u}}$

Wikipedia

(2019u).

Chow

mein. http://www.wikizero.biz/index.php? $\mathrm{q}=\mathrm{aHR0cHM}$ 6Ly9lbi53aWtpcGVkaWEub3JnL3dpa2kvQ2hvd $\underline{19 t Z W l u}$

Wikipedia (2019ü). Spring roll. http://www.wikizero.biz/index.php?q=aHR0cHM 6Ly9lbi53aWtpcGVkaWEub3JnL3dpa2kvU3Bya W5nX3JvbGw

Wikipedia (2019v). Peking duck. http://www.wikizero.biz/index.php?q=aHR0cHM 6Ly9lbi53aWtpcGVkaWEub3JnL3dpa2kvUGVra W5nX2R1Y2s

Wikipedia, (2019ö). Çin. http://www.wikizero. biz/index.php?q=aHR0cHM6Ly90ci53aWtpcGVk aWEub3JnL3dpa2kvw4dpbg

Wright, D.C. (2011). The history of China (2. Ed.). ABCCLIO, LLC, California, USA.

Zhang, Q. (2015). An introduction to Chinese history and culture. Springer-Verlag Berlin, Germany. 